\title{
FLOOD DAMAGES ASSESSMENT - CASE STUDY
}

\author{
M. ZELE ̌̌ÁKOVÁ', L. GA
}

\begin{abstract}
Flood damages assessment - case study. The article deals with the resolution of the problem of managing flood risk with the aim of effective management focusing on reducing flood risks and thus increasing the measure of flood protection. It is elaborated in the sense of currently valid Slovak legislation in the field of flood protection, primarily according to the Directive 2007/60/EC on the assessment and management of flood risks. Assessment of potential flood damage is carried out for the town of Medzev, which was in the scope of preliminary assessment of flood risk in Slovakia evaluated as an area with an existing potentially significant risk of flood. Given the preliminary results, we can state that in the studied location of Medzev the construction of flood protection measures makes sense, mainly in relation to the protection of property.
\end{abstract}

Keywords: flood risk, economic damages, loss curves, flood protection measures.

\section{INTRODUCTION}

At present, there are clear trends around the world that indicate that the hazard of the river basin is increasing in the coming period. The extent and the extreme nature of the flood episodes point to the need for a comprehensive design of the constructions, supplementing flood protection measures in potentially flooded areas (Houghton et al., 2001). Following the floods in the summer of 2002, several EU Member States have directed the attention of the Council of the European Union to the issue of flood prevention and protection. In October 2004, the Council adopted European flood action programs, which, following the adoption of the relevant legislative procedures, will be common to all Member States of the European Union through a binding legal instrument based on the consistency of the opinion of the European Parliament and the Council. On 23 October 2007, this initiative led the European Parliament and the Council to adopt Directive 2007/60/EC on the assessment and management of flood risks. The purpose of the Directive is to establish a framework for the assessment and management of flood risks at Community level in order to reduce the adverse impacts of floods on human health, the environment, economic activity and cultural heritage.

In the context of meeting the Directive's objectives, risk and risk assessment and risk analysis methods are gaining more and more attention, as they allow us to assess the effectiveness of mitigation and investment optimization costs (Ganoulis,

1 Technical University of Kosice, Faculty of Civil Engineering, Vysokoškolská 4, 04200 Kosice, Slovakia, E-mail: martina.zelenakova@tuke.sk

2 Slovak Water Management Enterprise, Košice Branch Office, Ďumbierska 14, 04159 Košice, Slovakia E-mail: lenka.ganova@tuke.sk 
2003) (Hardmeyer, Spencer, 2007). The development of risk analysis methods is closely related to the classification of the territory according to its vulnerability, mathematical modeling of rainfall-drainage processes and water flows during the floods and damage assessment. Generally speaking, the most methods for determining potential flood damage used in the world are based on the same principle of using the loss curve method.

The use of mathematical models and geographic information systems has become a common tool for evaluating and interpreting data in the flood management. The purpose of deploying these tools are in particular to speed up the process of risk analysis processing in flood areas and the subsequent mapping of flood damage and risks. It is also a goal to also use data sources that would be readily available, maintained over time, and have a uniform form throughout the territory. It is also a common tool used in flood management, respectively instrument in the decisionmaking process. Flood risk management is a decision-making process following the results of the flood risk assessment process. The goal of this process is to propose an optimal way of reducing the risk to an acceptable level. The process of flood risk management by evaluation of flood damages in Medzev city in the southeastern Slovakia.

\section{STUDY AREA}

City of Medzev (Figure 1) belongs to Košice district and its surroundings in the Košice region (south Slovakia), was selected for the assessment of potential flood damage and flood risk.

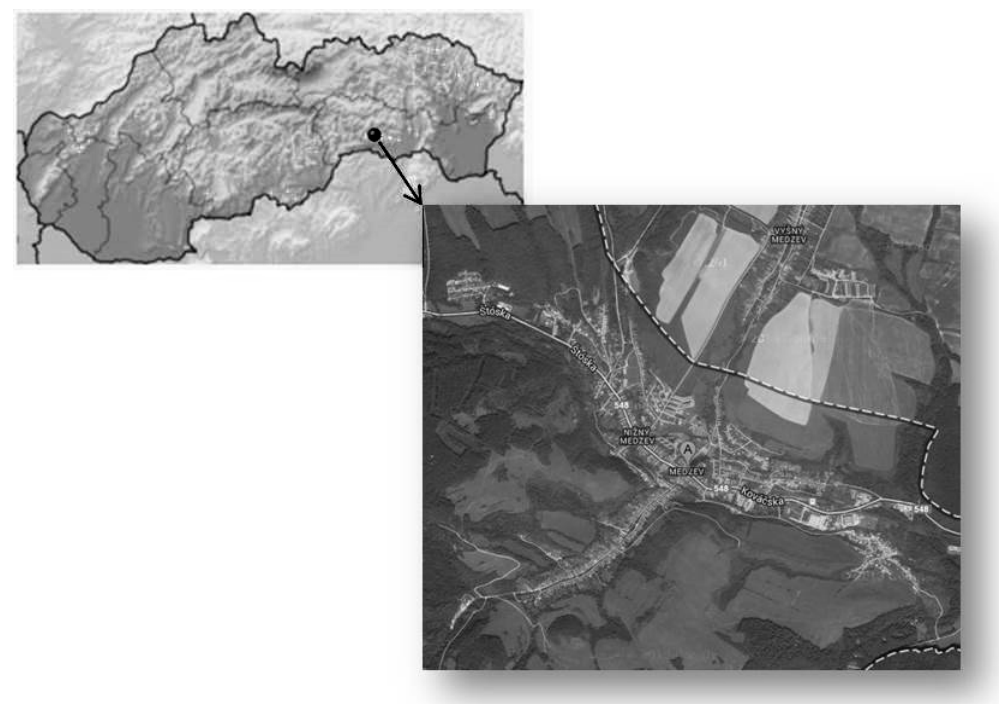

Fig. 1. Location of Medzev within Slovakia 
Bodva watercourse flows through the town. The watercourses Bodva is classified as significant watercourses and has potential of flood occurence. As the town of Medzev wass included in 2011 on the basis of a preliminary flood risk assessment among areas with an existing flood risk, it is essential to address this area as a matter of priority. In this area, it is necessary to build up flood protection measures that will be effective not only in terms of protection but also in economic, social and environmental terms.

The aim of this part of the article is the objective quantification of flood damage and flood risks in the locality, which are subsequently classified in terms of efficiency and acceptability.

\section{MATERIAL AND METHODS}

At present, as well as in this paper, the attention is paid mainly to property damage (economic damage). The extent of economic losses depends primarily on the co-ordination of flood and territorial factors. The calculation of the individual categories of damage requires a separate approach and different inputs.

The problem of the evaluation of the potential flood damage on property is very well elaborated in the Czech Republic in the dissertation thesis (Horský, 2008), which was later used in the same year in the proposal "Methodology of Determination of Flood Risks and Damage in Flooded Areas" (Drbal et al., 2008). Direct potential flood damage is determined in these publications by a procedure based on the application of damage curves, respectively loss curves.

Due to the very similar building and infrastructure solutions in the Slovak and the Czech Republic, the modified methodology proposed in the Czech Republic is used for the calculation of property damage in this work in town in Slovakia.

Potential direct flood damage is based on the application of the loss curves, which is based on the acquisition prices of each of the assessed categories of objects and on the loss functions created by the detailed analysis of flooding on individual categories of buildings and parts of structures according to the structure of the building components craft divisions according to the classification of the uniform of construction sites (Drbal et al., 2008). The difference is at acquisition prices, which are derived from the average budget price per unit of measure in the construction industry by UNIKA published by the Institute of Building Economics (2012).

For the calculation of direct potential flood damage to property, a general relationship is used (Horský, 2008), which is modified in the following form (1):

$$
\check{S}_{M i k}=V_{i k} C_{k} S_{k}
$$

where:

$\check{S}_{\text {Mik }}$ is the value of the quantified damage of the given object $i$ in the category $k[€]$,

$i$ the object index in the given category $k$, 
$k$ the index of individual rated categories of the construction,

$V$ the size or amount of affected object by category [pcs, $\left.\mathrm{m}, \mathrm{m}^{2}, \mathrm{~m}^{3}\right]$,

$C$ unit price of the unit of measure according to the rated category $[€ / \mathrm{pc}$;

$\left.€ / \mathrm{m} ; € / \mathrm{m}^{2} ; € / \mathrm{m}^{3}\right]$;

$S$ is the loss for each category, expressed in terms of flooding or depth of flooding [\%].

The basic principle of the calculation of damage for each category of construciton is still the same; the difference is only in units of measure and their prices, where the objects are generally calculated in length units $[\mathrm{m}]$ in the case of engineering networks and in the case of buildings in units of obsolete space $\left[\mathrm{m}^{3}\right]$ of agricultural land in area units $\left[\mathrm{m}^{2}\right]$.

Each loss curve is expressed in a range of potential damage values. The upper (max) and lower (min) limits of the damage are used due to different possibilities of applying faults of individual parts of the structure to the resulting damage. The loss curves used in the calculation can be of a dual type (Drbal et al., 2011):

- dependent on the depth of flooding in building objects and

- not-dependent on the depth of flooding - engineering networks, infrastructure and agriculture.

Property damage is calculated for each category according to the following relationship (2):

$$
\check{S}_{M k}=\sum \check{S}_{M i k}
$$

where:

$\check{S}_{M k}$ is the value of the quantified damage in the category $k[€]$,

$\breve{S}_{M i k}$ is the value of the quantified damage of the given object also in the category $k[€]$.

Then the total damage to property in the valued territory is calculated as the sum of the losses of the individual asset categories for the given $Q_{\mathrm{N}}$ as follows (3):

$$
\check{S}_{M}=\sum \check{S}_{M k}
$$

where:

$\check{S}_{M}$ is the value of the total quantified damage to the asset [€],

$\check{S}_{M k}$ is the value of the assessed damage in the category $k[€]$.

The following data and procedures for the determination of potential flood damage on assets, by category of buildings are described below, as well as the determination of their unit and loss rates. We have used the Proposals of the average budget price per unit of measure for 2012 (UNIKA, 2012).

\section{RESULTS}

According to the proposed methodology, the contents of this section is divided into three steps:

1. Estimation of potential flood damage to property. 
2. Calculation of flood risk based on the assessment of the extent of damages for designated floodplains and the probability of their occurrence.

3. Selection of cost-effective flood protection measures, which at the same time meet the levels of environmental and social risk acceptance as a result of floods.

The result is a proposal of possible flood protection objects that will be effective in terms of protection, as well as from an economic, social and environmental point of view.

Following the proposed methodology, the first group of damage to property is the damages to buildings.

The methodology for quantifying flood damage on property is based on the procedures based on the application of the loss curves, the mapping of the assets distribution in floodplains (Fig. 2) and the local survey of the site.

A key document for assessing the potential flood damage to the town of Medzev is "Town Plan of Medzev" prepared by Envio s.r.o. in 2013 and flood maps provided by DHI (Danish Hydraulics Institute) Slovakia, s.r.o..

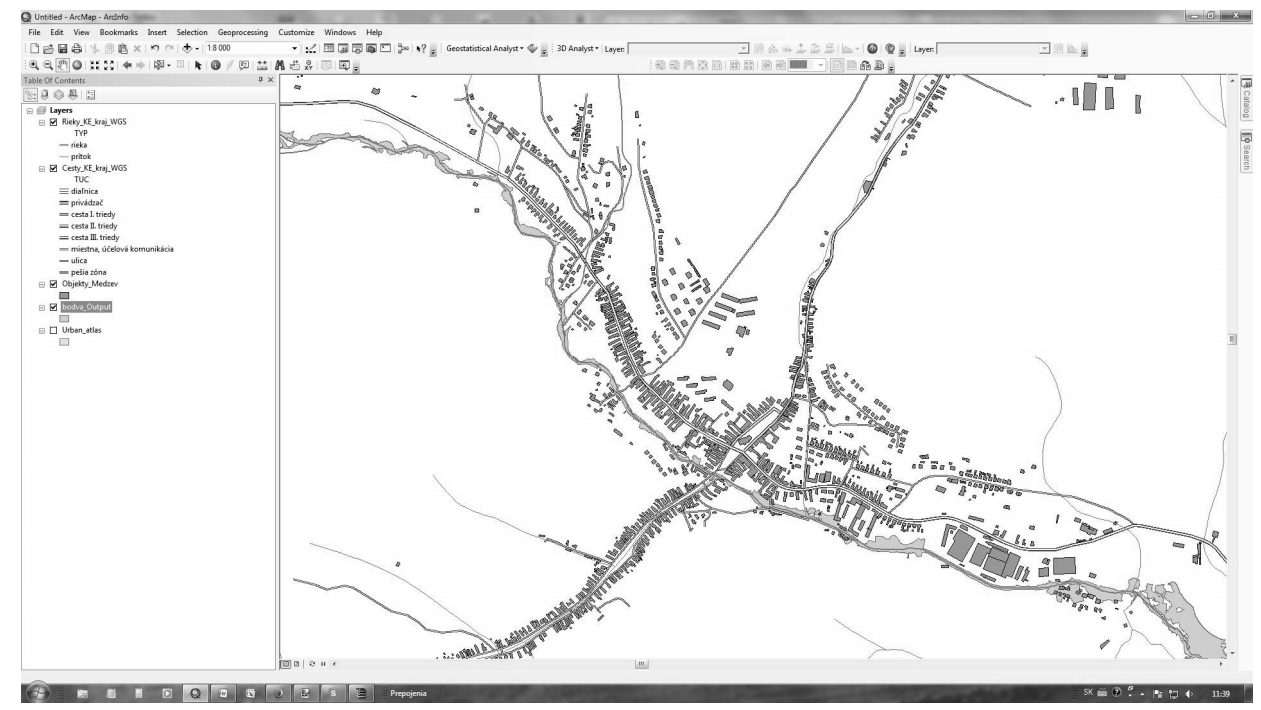

Fig. 2. Flooded buildings range for $Q_{5}$ (ArcGIS 10 output)

The calculation of flood damage to buildings is based on a basic relationship (1) where total damage is calculated as the sum of damage to individual buildings (3). For each building, the damage is calculated depending on the area of the building, the depth of flood and the average purchase price per $1 \mathrm{~m}^{2}$ of one storey building. For simplicity and due to the poor detail, only one type of building is considered, assuming a standard height of one storey of $3 \mathrm{~m}$. The resulted flood damages (min and max) at buildings are calculated and presented for diferent return period in Table 1. 
Table 1. Flood damages for different return periods of discharge

\begin{tabular}{|c|c|c|}
\hline \multirow{2}{*}{$Q_{\mathrm{N}}$} & \multicolumn{2}{|c|}{ Damages at buildings $\check{S}_{\mathrm{B}}[€]$} \\
\cline { 2 - 3 } & $\min$ & $\max$ \\
\hline$Q_{5}$ & 109753,30 & 166609,40 \\
\hline$Q_{10}$ & 136096,50 & 209278,70 \\
\hline$Q_{50}$ & 757690,00 & 1178341,80 \\
\hline$Q_{100}$ & 838069,50 & 1304582,10 \\
\hline$Q_{1000}$ & 1121201,40 & 1754652,30 \\
\hline
\end{tabular}

The aim of the paper was an estimate or, respectively, calculation of potential flood damage to property in the floodplains of Medzev (Figure 2). In the Tab. 1, the values of potential flood damage in the range of values in which the actual damage (min, max) in euros for individual flows $Q_{5}, Q_{10}, Q_{50}, Q_{100}$ and $Q_{1000}$ should be measured.

Based on this calculation the necessity of flood protection measure should be designed. The most effective measure will be the construction of the dry basin above the town at the Bodva River. This dry basin is also included in flood managements plans for Bodva river basin (MoE, 2015).

\section{CONCLUSIONS}

The main reason for calculating potential flood damage is the proposal for a procedure to select the most cost-effective combinations of measures to reduce the impact of floods on human health, the environment and their assets, which will serve as a basis for drawing up flood risk management plans. The essence is to create a conceptual framework that can and must be adapted to the nature and needs of each river basin. This ensure a consistent approach and the necessary effectiveness in flood risk management plans that was completed by Member States by 2015 as required by Directive 2007/60/EC on the assessment and management of flood risks and will be revised in 2021.

It is important to keep in mind that a flood in a modern economy is expected to bring about a whole gamut of consequences. The costs of damage caused by extreme weather events (among which floods are a major category) have shown a rapid upward trend globally. The scope and extremity of flood episodes point to the need to design and build a comprehensive system of flood protection measures in potential flood areas. The main goal of the paper is the proposal of a process of assessment of flood risk with the aim of reducing adverse consequences on the economic activities associated with floods. The consequences of flooding can take many forms, whether material damage, injury, deaths, environmental contamination, etc. Potential flood damage is related to movable and immovable property and variously defined natural and landscape values in the inundated areas. In this paper the process for determining the potential flood 
damage to property (economic damage) is applied with aim of effective flood protection in the area. $1 / 0278 / 18$.

This work has been supported by the Scientific Education Agency project

\section{REFERENCES}

1. Drbal, K. et al. (2008), The methodology for setting flood risk and flood damage in the area (in Czech). Brno: WRI TGM.

2. Drbal, K. et al. (2011), Maps of the risks arising from the flood hazard in the country (in Czech). Final Report. Brno: WRI TGM.

3. Ganoulis, J. (2003), Risk-based floodplain management: a case study from Greece. Int J River Basin Manag, 1:41-47.

4. Hardmeyer, K, Spencer, M.A. (2007), Bootstrap methods: another look at the Jackknife and geographic information systems to assess flooding problems in an urban watershed in Rhode Island. Environ Manag, 39:563-574.

5. Horský, M. (2008), Methods of potential flood damages assessment and its application using GIS (in Czech). Thesis. Praha: Faculty of Civil Engineering.

6. Houghton, J.T. et al. (2001), Climate Change: The Scientific Basis. Contribution of Working Group I to the Third Assessment Report of the Intergovernmental Panel on Climate Change. WMO and UNEP.

7. *** (2007) Directive on the assessment and management of flood risks. Official J, L288, pp. 27-34. Brussels: The European Parliament and the Council of the European Union, (2007/60/EC)

8. *** (2015) Flood risk management plan in Bodva river basin. Ministry of Environment of the Slovak Republic Available at http://www.minzp.sk/. 